Alexandre Caporal

Avaliação de ativos de geração hidrelétrica através da Teoria de Opções Reais em Tempo Discreto

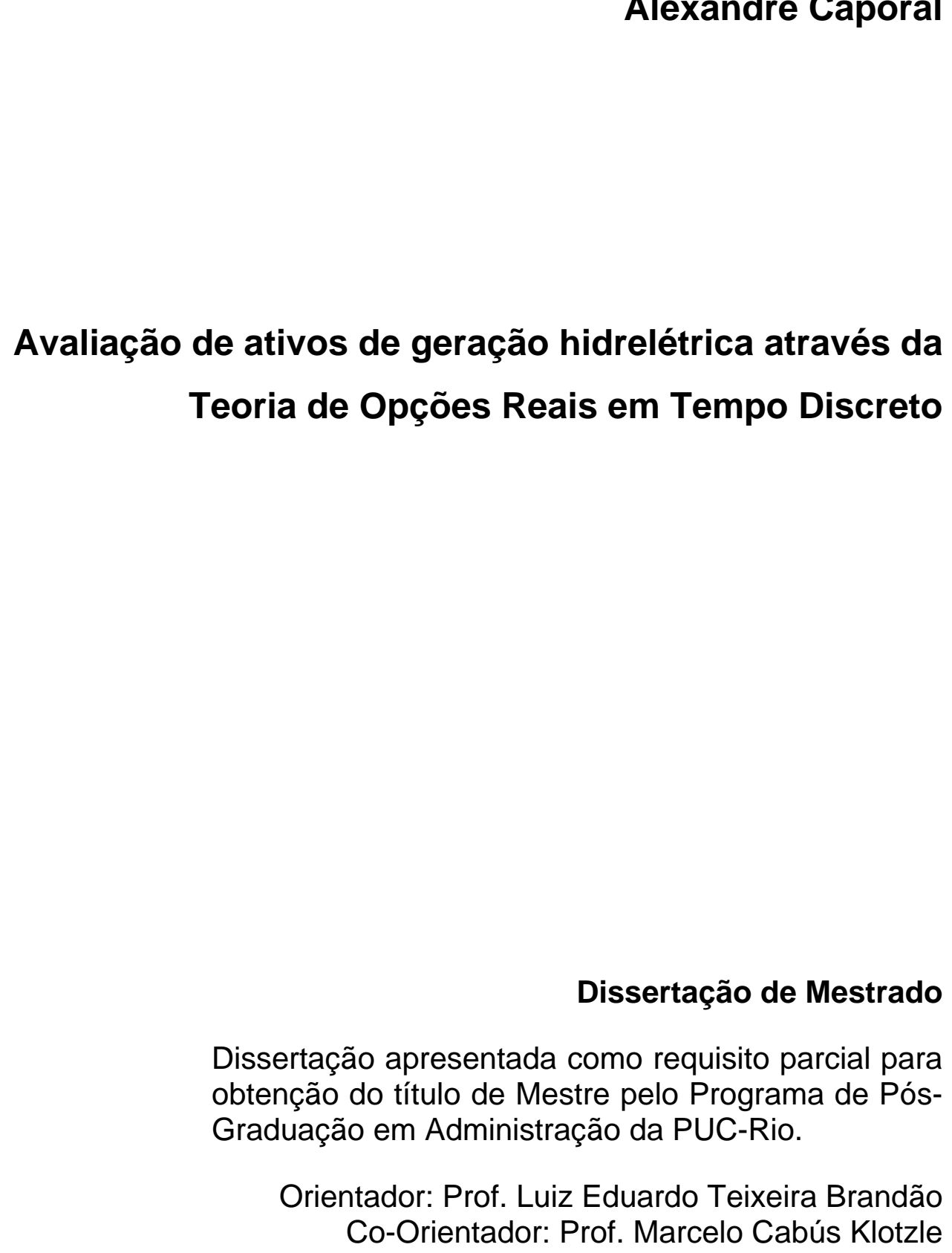

Rio de Janeiro, agosto de 2006 
Alexandre Caporal

\section{Avaliação de Ativos de Geração Hidrelétrica através da Teoria de Opções Reais em Tempo Discreto}

Dissertação apresentada como requisito parcial para obtenção do grau de Mestre pelo Programa de Pósgraduação em Administração de Empresas da PUC-Rio. Aprovada pela Comissão Examinadora abaixo assinada.

Prof. Marcelo Cabus Klotzle Departamento de Administração - PUC-Rio

Prof. Antonio de Araújo Freitas Júnior FGV

Prof. João Pontes Nogueira Vice-Decano de Pós-Graduação do CCS 
Todos os direitos reservados. É proibida a reprodução total ou parcial do trabalho sem autorização da universidade, do autor e do orientador.

\section{Alexandre Caporal}

Graduou-se em Administração de Empresas pela UFF em 2001 e concluiu o mestrado em Administração de Empresas pela PUC RIO em 2006. Atuou nas áreas de planejamento estratégico, financeiro e gestão financeira em empresas multinacionais de grande porte. Seus interesses de pesquisa estão relacionados à avaliação de projetos de investimento, avaliação de desempenho corporativo, administração de recursos de terceiros e planejamento estratégico.

Ficha Catalográfica

Caporal, Alexandre

Avaliação de ativos de geração hidrelétrica através da teoria de opções em tempo discreto / Alexandre Caporal ; orientador: Luiz Eduardo Teixeira Brandão ; coorientador: Marcelo Cabús Klotzle. - Rio de Janeiro : PUC, Departamento de Administração, 2006.

77 f. : il. ; $30 \mathrm{~cm}$

Dissertação (mestrado) - Pontifícia Universidade Católica do Rio de Janeiro, Departamento de Administração.

Inclui referências bibliográficas.

1. Administração - Teses. 2. Finanças. 3. Opções reais. 4. Análise de projetos. 5. Flexibilidade gerencial. 6. Análise de decisões. I. Brandão, Luiz Eduardo Teixeira. II. Klotzle, Marcelo Cabús. III. Pontifícia Universidade Católica do Rio de Janeiro. Departamento de Administração. IV. Título.

CDD: 658 
“Não é um notável talento o que se exige para assegurar o êxito em qualquer empreendimento, mas sim um firme propósito "

Thomas Wittlam Atkinson 


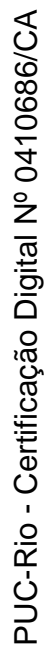

A minha família e a todos que me ajudaram nesta empreitada 


\section{Agradecimentos}

Agradeço aos professores Luiz Brandão e Marcelo Cabús pela orientação e todo apoio neste trabalho.

Aos amigos de turma por todo apoio, troca de idéias, opinião, ajuda em diversas ocasiões e principalmente pela excelente convivência.

A minha família por toda compreensão e apoio em todos os momentos e decisões da minha vida. 


\section{Resumo}

Caporal, Alexandre; Brandão, Luiz Eduarto Teixeira. Avaliação de ativos de geração hidrelétrica através da Teoria de Opções Reais em Tempo Discreto. Rio de Janeiro, 2006. 77p. Dissertação de Mestrado Departamento de Administração, Pontifícia Universidade Católica do Rio de Janeiro.

O setor elétrico brasileiro vem sofrendo fortes mudanças estruturais, cujo principal objetivo é criar um caráter competitivo para permitir ao setor crescer não mais por investimentos estatais, mas sim pela atuação do capital privado. Assim sendo, a Agência Nacional de Energia Elétrica (ANEEL) passa a oferecer uma multiplicidade de oportunidades de investimentos, geradas principalmente pela recente implantação dos leilões de unidades geradoras de energia (em sua maioria hidrelétricas) e de linhas transmissoras. Em vista disso, essa dissertação propõe um modelo de avaliação de projetos de geração hidrelétrica sob condições de incerteza utilizando-se a metodologia de opções reais. Este trabalho busca incorporar a flexibilidade gerencial à avaliação de projetos através do uso de Árvores Binomiais de Decisão, com probabilidades neutras ao risco, para a avaliação por Opções Reais em Tempo Discreto. O método é computacionalmente intenso, mas de modelagem mais simples e intuitiva que os métodos tradicionais de Opções Reais, permitindo assim uma maior flexibilidade na elaboração do modelo. A aplicação prática foi realizada através da avaliação da opção de venda de energia de uma Pequena Central Hidrelétrica $(\mathrm{PCH})$.

\section{Palavras-chave}

Finanças; Opções Reais; Análise de Projetos; Flexibilidade Gerencial; Análise de Decisões 


\section{Abstract}

Caporal, Alexandre; Brandão, Luiz Eduarto Teixeira. Hydroeletric Generation Asset Valuation by Real Options in Dicrete Time. Rio de Janeiro, 2006. 77p. Dissertação de Mestrado - Departamento de Administração, Pontifícia Universidade Católica do Rio de Janeiro.

The Brazilian electric sector comes suffering strong structural changes, whose main objective is to create a competitive to allow the sector to grow not more for state investments, but for the private capital. The Agência Nacional de Energia Elétrica (ANEEL) starts to offer a multiplicity of chances of investments, generated mainly for the recent implantation of the auctions of generating units of energy (in its hydroeletrics majority) and of transmission lines. In sight of this, this work propose a model to hydroelectric generation asset valuation under uncertainty conditions using real options methodology. This work aims to incorporate managerial flexibility to the projects valuation using Decision Trees, with neutral probabilities to the risk, for the Real Options Valuation in Discrete Time. The method is computational intense, but simpler and more intuitive than the traditional methods of Real Options, thus allowing a bigger flexibility in the modeling of the problem. The practical application is applied to the problem of option of energy sale valuation of Small Hydroeletric Generation Asset.

\section{KeyWords}

Finance; Real Options; Capital Budgeting; Managerial Flexibility; Decision Analysis 


\section{Sumário}

1 Introdução 13

$\begin{array}{ll}1.1 \text { O problema } & 13\end{array}$

$\begin{array}{ll}1.2 \text { Objetivos da Dissertação } & 14\end{array}$

$\begin{array}{ll}1.3 \text { Delimitação do Estudo } & 15\end{array}$

$\begin{array}{ll}1.4 \text { Estrutura da Dissertação } & 15\end{array}$

2 Referencial Teórico 16

2.1 Teoria das Opções Reais 16

$\begin{array}{ll}2.2 \text { Presença de Riscos e Incertezas } & 17\end{array}$

2.3 Analogia com Opções Financeiras 18

2.4 Apreçamento de Opções (Modelo Black-Scholes) 21

2.5 Modelo Binomial 24

2.6 Decision Tree Analysis (DTA) 25

2.7 Movimento Geométrico Browniano 29

2.8 Simulação de Monte Carlo 31

2.9 Tipos de Opções Reais $\quad 32$

3 Mercado de Energia Elétrica no Brasil 35

3.1 Histórico 35

3.2 O Novo Modelo do Setor Elétrico 36

3.3 Pequenas Centrais Hidrelétricas ( $\mathrm{PCH}^{\prime} \mathrm{s}$ ) 37

3.4 Procedimentos para implementação de $\mathrm{PCH}^{\prime}$ s no Brasil 37

3.5 Mecanismos de Venda de Energia Produzida por PCH 39

3.5.1 Power Purchase Agreement - PPA 40

$\begin{array}{lll}3.5 .2 & \text { PROINFA } & 41\end{array}$

3.5.3 Câmara de Comercialização de Energia e o mercado Spot 41

3.6 Preço Spot de Eletricidade no Brasil 43

4 Modelo Teórico $\quad 47$

$\begin{array}{ll}\text { 4.1 Premissas Teóricas } & 47\end{array}$

4.2 Avaliação - Modelagem em Tempo Discreto 47 
5 Aplicação ao Caso de uma Pequena Central Hidrelétrica (PCH) 54

5.1 Introdução 54

5.2 Premissas 54

5.3 Modelo Financeiro 55

5.3.1 Potência Instalada 55

5.3.2 Custo do Investimento 56

5.3.3 Geração Total de Energia 56

5.3.4 Custo de Geração 56

5.3.5 Preço de venda da Energia 56

5.3.6 Taxa de Desconto e Taxa Livre de Risco 58

5.3.7 Vida Útil $\quad 59$

5.4 Modelagem Financeira $\quad 59$

5.5 Flexibilidade Gerencial do Projeto: Opções Reais 60

5.5.1 Opção de Contratar 60

5.6 Solução 62

5.6.1 Modelagem Determinística: FCD sem Opções 62

5.6.2 Determinação da Volatilidade do Projeto 63

5.6.3 Determinação do Risco do Projeto 64

5.6.4 Árvore do Projeto 64

5.6.5 Opção de Contratação 66

6 Conclusões e Recomendações 71

6.1 Conclusões 71

6.2 Limitações da Metodologia 72

6.3 Sugestões para Trabalhos Futuros 73

7 Referências Bibliográficas $\quad 74$

8 Anexos $\quad 76$ 


\section{Lista de figuras}

Figura 1 - Valorização de uma opção de compra no vencimento $\quad 19$

Figura 2 - Valorização de uma opção de venda no vencimento 20

Figura 3 - Variação do preço da ação e da opção em uma árvore binomial 24

Figura 4 - Representação de um portfólio replicante 26

Figura 5 - Representação da Simulação de Monte Carlo

para valor presente líquido

Figura 6 - Fluxograma das atividades presentes no estudo

e no projeto básico de PCHs 38

Figura 7 - Contabilização da energia disponível no sistema 42

Figura 8 - Planejamento da operação e possíveis preços

futuros do spot

Figura 9 - Evolução preço CMO 45

Figura 10 - Árvore de Eventos $\quad 49$

Figura 11 - Árvore de Decisão $\quad 52$

Figura 12 - O processo de avaliação em quatro etapas 53

Figura 13 - Modelo Binomial do Projeto 65

Figura 14 - Árvore de Decisão do Projeto 66

Figura 15 - Árvore de decisão com opção de contratação

nos anos 0, 5, 10 e 15

Figura 16 -Valor do Projeto com a Opção de Contratar 68

Figura 17 - Política Ótima de Investimentos 69

Figura 18 - Valor do Projeto: Sensibilidade a volatilidade

do preço spot 69

Figura 19 - Valor do Projeto: Sensibilidade ao preço inicial spot $\quad 70$

Figura 20 - Valor do Projeto: Sensibilidade frente ao preço

spot e a volatilidade $\quad 70$ 


\section{Lista de tabelas}

Tabela 1 - Analogia entre opções financeiras e opções reais 21

Tabela 2 - Estatísticas descritivas do CMO (Set/00 a Dez/05) 45

Tabela 3 - Estatísticas descritivas do CMO (Jun/03 a Dez/05) 46

Tabela 4 - Parâmetros adotados para a avaliação da PCH 55

Tabela 5 - Fluxo de caixa Projetado 59

Tabela 6 - Opção de Contratação da PCH 61

Tabela 7 - Resultados da Simulação de Monte Carlo 63 